\title{
ANDRAGOGIA: UMA EDUCAÇÃO DIFERENCIADA PARA O ALUNO ADULTO
}

\author{
Mariane Della Coletta Savioli Garzotti de Araujo, Verônica Nogueira Vanni, Carmen Lúcia Dias
}

Universidade do Oeste Paulista - UNOESTE, Mestrado em Educação, Presidente Prudente, SP. E-mail: mariane.aee@gmail.com

\section{RESUMO}

Este artigo destaca a importância de haver um ensino que seja direcionado para as habilidades e competências do aluno adulto, isso porque adultos e crianças, além de aprenderem de forma diferente, possuem em seu cotidiano dinâmicas distintas das crianças, o que implica ao educador propor estratégias de ensino e motivações adequadas a este público. $O$ intuito de buscar quais as melhores metodologias a serem aplicadas no ensino de pessoas adultas, requer intrinsecamente analisar o perfil do professor andragógico assim como o perfil deste aluno. Diferentes estratégias e adequações devem ocorrer, pois ao longo dos anos, diante de mudanças sociais, históricas e tecnológicas que alteraram o cotidiano do aluno adulto, o professor deverá buscar meios diferenciados para ensiná-los. E a Andragogia, como um caminho educacional que busca compreender o adulto, se reflete em um somatório de trocas de conhecimentos entre o facilitador e o estudante adulto, tornando a aprendizagem mais significativa.

Palavras-chave: Andragogia. Educação de adultos. Perfil do professor. Aprendizagem. Estratégias.

\section{ANDRAGOGY: A DIFFERENTIATED EDUCATION FOR THE ADULT LEARNER}

\begin{abstract}
This article highlights the importance of having an education system that is directed to the skills and competences of the adult learner, this is because adults and children, in addition to learning in a different way, have in their daily life dynamics distinct from children, which implies that educators propose teaching strategies and motivations appropriate to this public. To what are the best methodologies to be applied in the teaching of adults, requires intrinsically analyze the profile of professor andragógico as well as the profile of the student.

Different strategies and adaptations must occur, because over the years, in the face of changing social, historical, and technological that changed the daily lives of adult students, the teacher should seek differentiated means to teach them. And Andragogy, as an educational path that seeks to understand the adult, is reflected in a sum of exchanges of knowledge between the facilitator and the adult student, making learning more meaningful.
\end{abstract}

Keywords: Andragogia. Adults education. Profile of the teacher. Apprenticeship. Strategies. 


\section{INTRODUÇÃO}

A Andragogia é conceituada entre outros, como a ciência que estuda a educação do aluno adulto, diferenciando-se da Pedagogia que estuda como a criança aprende.

É sabido que ao longo dos tempos, imergiram inúmeras pesquisas sobre quais as melhores estratégias e quais os conteúdos necessários a serem desenvolvidos com os adultos no âmbito escolar. Observa-se neste tocante, que diversos autores contrapõem os termos Pedagogia e Andragogia, como se estas ciências fossem divergentes, quando o que se difere na realidade são os métodos e estratégias a serem desenvolvidos junto ao indivíduo, devendo consideradas as mudanças históricas, sociais e tecnológicas que fazem parte do cotidiano do aluno adulto, pois é este o foco da educação Andragógica.

Sendo esta, questionadora do modelo educacional aplicado aos adultos, procura conhecer as particularidades da aprendizagem do aluno maduro, afim de adequar ou promover métodos didáticos eficazes e de qualidade propostos especificamente nessa população.

Neste contexto, este artigo, embasado na revisão bibliográfica de estudiosos no assunto, propõe expor as ideias dos mesmos sobre a educação Andragógica para que melhor se possa compreender a importância desta no ensino de pessoas adultas, com o intuito de conhecer, refletir e complementar as estratégias metodológicas na educação do aluno adulto.

\section{A ANDRAGOGIA ATRAVÉS DOS TEMPOS}

A Andragogia sofreu alterações tanto em seu conceito, quanto em seu método, pois historicamente, a sociedade, assim como a economia, a educação e a tecnologia, causaram modificações na dinâmica social e portanto, a educação de adultos necessitou acompanhá-las. Pela primeira vez, no ano de 1833, o alemão Alexander Kappa, introduziu o termo Andragogia, relacionando-a com a teoria educacional de Platão, esta teoria foi retomada no século XX por Eugen Rosenback, que embasou-se nos conteúdos curriculares adequados a educação de adultos (BENEDICTO, 2004).

Eduard C. Lideman, estudioso norte americano, é considerado um dos maiores contribuidores da pesquisa sobre o tema "Educação de Adultos", através do seu trabalho publicado em 1926, intitulado "The Meaning of Adult Education", sob influência de John Dewey. Lideman, identificou 5 pressupostos importantes para a educação de adultos-e que se transformaram em suportes para as pesquisas sobre o tema, sendo hoje fundamentos para a teoria da aprendizagem de adultos (OLIVEIRA, 2007). 
Para Gomes, Pezzi e Bárcia (2006), os princípios da Andragogia e as teorias que sinalizam uma pedagogia voltada para o aluno, estão trazendo maiores contribuições no trabalho com adultos. Muitos outros pesquisadores, tais como Edward L. Thorndike e Lawrence P. Jacks, contribuíram na ampliação dos estudos sobre o desenvolvimento da Andragogia como ciência da educação de adultos, sendo esta, a concepção que abarcamos até os dias atuais.

Até o ano de 1940, os elementos para a elaboração de uma teoria da aprendizagem dos adultos, estavam dispersos, necessitando de uma unificação teórica, essa unificação, só aconteceu entre 1940 e 1950, quando foram relacionados com conhecimentos de outras ciências humanas, dentre elas a psicoterapia. A psicoterapia traz alguns nomes que contribuíram com a Andragogia, destacando entre eles: Sigmund Freud, Carl Jung, Erick Erikson, Abraham H. Maslow, Carl R. Rogers. (OLIVEIRA, 2007).

Dentre vários pesquisadores do tema abordado neste artigo, também destacamos principalmente Malcolm Knowles, que disseminou através de suas publicações conceitos fundamentais que o mesmo utilizou na construção do modelo andragógico de Educação.

Knowles, na obra de sua autoria "The Adult Learner a Neglected Species", auxiliou na reformulação da Teoria de Aprendizagem de Adultos em 1950. (SILVA, 2012).

A partir dos referidos fatos históricos, começou a construção do modelo andragógico de educação, sendo uma antítese do modelo pedagógico: “Andragogia x Pedagogia". Assim, preconizou as premissas da educação dirigida pelo professor, deixando ao aprendiz somente o papel de submissão. Essas premissas são adiante reformuladas, tornando o aprendiz adulto, como sujeito da educação e não um mero objeto da mesma.

Na Venezuela, Adan Felix (1987), foi o precursor da Andragogia, conceituando-a como a ciência e a arte de instruir e educar os homens permanentemente em qualquer período psicológico em termos de sua vida cultural (SILVA, 2012).

Atualmente, concebe-se a educação andragógica essencial para a promoção permanente do homem, pois é a educação torna esse aprendiz adulto, mais participativo efetivamente na sociedade que o cerca, trazendo a ele uma elevada autoestima, maior conhecimento, inclusive para a vida profissional, assim como, prazer em viver e em tornar-se ou manter-se um ser social.

\section{CONCEITUANDO ANDRAGOGIA}

Há diversos conceitos de Andragogia, porém o que vai caracterizá-la como modelo educacional para alunos adultos é no sentido de proporcionar a aprendizagem à populações de diferentes níveis, podendo ser estas diferenças, socioculturais e de idade, tendo como conteúdos 
referenciais as ciências naturais e humanas. Tal caracterização acontece por sua flexibilidade e a aplicabilidade de seus modelos educativos diversificados (NOGUEIRA, 2004).

Entre os diferentes conceitos, podemos destacar Bellan (2005, p.20), que afirma se a andragogia, a "ciência que estuda como os adultos aprendem". A definição de Andragogia, do grego: andros - adulto e gogos - educar, propõe compreender como o adulto aprende, pois estes, de acordo com as experiências que são adquiridas no decorrer de suas vidas, assim como, com o aprendizado e o conhecimento que adquirem cotidianamente, buscando solucionar os desafios. Alunos adultos, assimilam e aprendem melhor quando o conteúdo está relacionado com o seu diaa-dia (BELLAN, 2005).

Hamze (2008) destaca em seus estudos a andragogia como um caminho educacional que busca compreender o adulto, podendo ser considerada uma teoria, mas também um método de ensino, que se reflete em um somatório de trocas de conhecimentos entre o facilitador do conhecimento e o estudante adulto e suas experiências de vida.

Na concepção do dicionário, Aluno "Legalmente, significa que um indivíduo pode ser parte de um contrato. A mesma idade mínima, ou outra diferente, pode ser aplicável para, por exemplo, definir quando os pais perdem direitos parentais ou deixam de ter deveres para com a pessoa em causa, como o da responsabilidade financeira pelo menor." ${ }^{1}$

Segundo Ari Batista de Oliveira, Mestre em Andragogia pela Universidade de Minesota/EUA, Adulto é aquele indivíduo, que ocupa o status definido pela sociedade, por ser maduro o suficiente para dar continuidade à espécie e, coletivamente, é autodirigido, o que o torna capaz de responder pelos seus atos diante da sociedade (OLIVEIRA, 2007).

O adulto tem consciência de que precisa aprender. Segundo Knowles (1972, p. 17), a andragogia é a "arte e a ciência destinada a auxiliar os adultos a aprender e a compreender o processo de aprendizagem de adultos". Segundo Márquez (1998), "é a disciplina educativa que tenta compreender o adulto a partir de todos os componentes humanos, quer dizer, como um ser biológico e social". E Aquino (2007) referenda dizendo que a andragogia apresenta-se atualmente, como uma alternativa à pedagogia clássica e refere-se à educação centrada no aprendiz, para jovens e adultos.

\footnotetext{
${ }^{1}$ Adulto, aspecto legal, segundo Wikipédia, a enciclopédia livre. 


\section{O PAPEL DO PROFESSOR}

Essa experiência vivenciada, a partir da proposta da disciplina Prática Pedagógica, Aprendizagem e Desenvolvimento Humano, possibilitou aos alunos/docentes repensarem e reconstruírem suas próprias práticas pedagógicas quanto ao ensino de pessoas adultas.

O papel do professor na Andragogia se difere do Ensino Tradicional, pois para que este possa ter sucesso no aprendizado do aluno adulto, necessita, assumir outro perfil de educador, assim conseguirá desenvolver um ensino significativo e de qualidade. Esse perfil deve ser de facilitador da aprendizagem, pois nesta modalidade, o aluno adulto tem outra postura, como exemplo, a opinião própria, gostos e comportamentos muito diferentes de uma criança, daí a necessidade de técnicas de ensino diferentes e mais apropriadas a seu contexto e realidade. Dessa forma, afirma Freire (1992) "as relações do homem com o mundo, independem do fato de ser alfabetizado ou não, basta ser homem para realizá-las, para ser capaz de captar os dados da realidade, de saber, ainda que seja este saber meramente opinativo".

Segundo Nogueira (2004), o facilitador de aprendizagem está sempre presente no processo de aprendizagem e possui elevadas responsabilidades de orientação e facilitação deste processo. Corrobora com esta ideia Knowles (1980) afirmando que cabe ao facilitador da aprendizagem verificar quais os pressupostos adequados a uma dada situação. O mesmo autor afirma (1991), que se encontra explícito que o facilitador deve ter cuidado num primeiro momento de convívio com os formandos, esse momento pode ser designado pela expressão "quebra-gelo", a fim de fomentar as relações interpessoais, em desmistificar ideias erróneas e/ou preconceitos perante a aprendizagem, assim como em desenvolver uma imagem positiva dos adultos. Ainda, de acordo com Pratt (1993), os alunos adultos quando receosos ou ansiosos, inibem a sua expressão, e assim, somente conseguirão aprender, quando sentirem-se respeitados em suas diferenças, que seus erros e dificuldades na aprendizagem, não serão alvo de comentários e que a podem se sentir incentivados a colaborar, devem ser encorajados, pelo facilitador a da mesma forma, estarem motivados a terem relações de suporte interpessoal e de participação interativa.

Segundo Knowles (1984) para que se estabeleça essa relação de suporte e confiança, necessita que sejam disponibilizados na sala de aula, assim como em qualquer dos ambientes de aprendizagem, tanto recursos humanos, quanto os recursos materiais, o que torna o ambiente adequado para a aprendizagem.

Para que seja estabelecido um clima propício à aprendizagem, o facilitador é responsável em providenciar condições físicas favoráveis e confortáveis para que haja a interação entre alunos e destes com ele próprio, deverá sempre estabelecer uma relação de empatia com cada aluno 
adulto, enxergá-lo e respeitá-lo como pessoa que possui valores, sentimentos e ideias. Quando o professor facilitador respeita as individualidades de cada um de seus alunos adultos, como por exemplo chamando-o pelo nome, de acordo com Nogueira (2004), permite a construção de uma relação de confiança e ajuda mútua. Dessa forma, o facilitador de aprendizagem, também se sentirá à vontade para expor os seus sentimentos e da mesma forma, ainda afirma Nogueira (2004), irá contribuir com os seus recursos no espírito do questionamento mútuo, sendo esta, uma das diferenças mais notórias face ao professor que se pressupõe distante e fonte de sabedoria na maior parte das situações. Este deverá abandonar também todo e qualquer símbolo ou situação que lembre o aluno adulto de quando ele era uma criança, isso torna o ambiente e suas estratégias respeitosas ao modo e forma de aprender destes alunos.

\section{O ALUNO DA ANDRAGOGIA}

O aluno adulto é diferentemente da criança, um aluno mais responsável, mais ativo e atuante, é visivelmente motivado a realização de construção de sua própria aprendizagem. 0 aprendente na educação Andragógica, deverá perceber os objetivos de aprendizagem como seus, assim o facilitador, terá que envolvê-los num processo mútuo de construção e interação dos objetivos, para que assim, a necessidade do aprendente e do facilitador, sejam ambas respeitadas e consideradas.

O aluno adulto, afirma Chotguis, considera importante de acordo com sua necessidade:

- $\quad$ A Necessidade de Saber. Os adultos investem energia investigando o que ganharão em aprender algo, assim, necessitam saber por que aprender;

- $\quad$ Autoconceito do Aprendiz. Os adultos respondem ao autoconceito de serem responsáveis pela própria vida e pelo que acontece com ela, inclusive pelo que aprende;

- O Papel das Experiências dos Aprendizes. Os adultos acumulam mais experiências e de diferentes tipos, do que na juventude;

- $\quad$ Prontos para Aprender - PRONTIDÃO. Adultos estão prontos para aprender o que vai fazer diferença em sua vida cotidiana, em situações reais;

- A Orientação para a Aprendizagem. Alunos adultos são centrados na vida, assim como, em seus problemas, em suas tarefas, e em sua orientação para a aprendizagem.

- Motivação. As pressões internas, como desejo de satisfação no trabalho e autoestima são motivadores mais potentes para os adultos do que as externas, como melhor emprego, salário etc. (CHOTGUIS, sd). 
Para tanto, a responsabilidade no planejamento e condução das aprendizagens, são compartilhadas tanto entre os aprendente, quanto deste com o facilitador.

Knowles (1980) salienta que os alunos adultos, aprendentes, deverão construir um plano de conteúdos que pretendem aprender, e o professor facilitador, deverá a partir disto selecionar juntamente com os alunos os melhores métodos e materiais disponíveis e adequados à aprendizagem destes, envolvendo-os nas tomadas de decisão, considerando os objetivos previamente definidos.

\section{CONSIDERAÇÕES}

Diante da pesquisa realizada para a elaboração deste artigo, observa-se a presença de poucos estudos na área, necessitando-se de estudos mais aprofundados para uma maior aproximação entre a teoria e a prática do profissional docente do Ensino Superior e da Educação de adultos em geral. A Andragogia ainda hoje é um tema que necessita ser disseminado em maior escala no meio educacional, para que haja também uma aplicabilidade significativa, visto que a proposta Andragógica é de grande contribuição para a sociedade, pois, através dela a troca entre professor e aluno, aumenta consideravelmente o interesse de ambos na educação, consequentemente trazendo mais êxitos educacionais.

Constatamos ainda, que a Andragogia, por transitar em "territórios desconhecidos" por muitos educadores, requer um maior preparo acadêmico, daí a importância das contribuições dos autores abordados neste artigo, os quais possibilitam que estes planejem melhor sua didática para o aluno adulto em situação de aprendizagem de forma que impacte a sua vida, transformando-a de acordo com o interesse de cada indivíduo e abrindo perspectivas de êxito profissional.

\section{REFERÊNCIAS}

AQUINO, C. T. E. Como aprender: Andragogia e as habilidades da aprendizagem. 1 ed.. São Paulo: Person Prentice Haal, 2007.

BELLAN, Z. S., Andragogia em ação: como ensinar adultos sem se tornar Marcante. Santa Bárbara d'Oeste, SOCEP Editora, 2005.

BENEDICTO, S. C. Aprendizagem transformativa no espaço organizacional: uma análise da proposta andragógica da Petrobrás. Lavras: UFLA, 2004.

CHOTGUIS, J., Andragogia - Arte e ciência na aprendizagem do adulto - Disponível em: $<$ www.serprofessoruniversitario.pro.br> Acessado em 14/12/2014. 
FREIRE, P. Pedagogia da esperança: um reencontro com a pedagogia do oprimido. São Paulo: Paz e Terra. 1992.

GOMES, R. de C. G.; PEZZI, S. ; BÁRCIA, R. M.. Tecnologia e Andragogia: aliadas na educação a distância Tema: Gestão de Sistemas de Educação a Distância (2006), Disponibilizado em: http://www.abed.org.br/publique/cgi/cgilua.exe/sys/start.htm?infoid=121\&sid=121\&UserActiveT emplate=4abed, $<15$ de janeiro de 2015>.

HAMZE, A., Andragogia e a arte de ensinar aos adultos, Disponível em: $<$ http://www.educador.brasilescola.com/trabalho-docente/andragogia.htm>. Acessado em $14 / 01 / 2015$.

MARQUEZ, A. Andragogía: propuesta política para una cultura democrática en educación superior. Santo Domingo, República Dominicana, jul. 1998. Disponível em: <http://ofdp_rd.tripod.com/encuentro/ponencias/amarquez.html> Acesso em: 04/01/2015.

NOGUEIRA, S. M.. Andragogia: que contributos para a prática educativa?. Faculdade de Psicologia e de Ciências da Educação/Universidade de Coimbra - Portugal. Junho, 2004. Disponibilizado em: file://D:/Meus\%20Documentos/Downloads/1226-2031-1-PB\%20(2).pdf , <02 de janeiro de 2015>.

OLIVEIRA, A. B. Andragogia - Introdução. 2007. Disponível em: <http:www.terravista.pt/Meco/4678/andragogia.htm> Acesso em: 08 de janeiro de 2015.

A, B. de. Andragogia - a educação de adultos. 2007. Disponível em:

< http://www.serprofessoruniversitario.pro.br/ler.php?modulo=1\&texto=13 > Acesso em: 20 de dezembro de 2014.

PRATT, D. D.. Andragogy after twenty-five years. New directions for adult and continuing education. Volume 1993, Issue 57, Spring 1993, Pages: 15-23, Article first published online : 18 AUG 2006, DOI: 10.1002/ace.36719935704,<15 de janeiro de 2015>.

KNOWLES. M. S. Andragogía no Pedagogía. Centro Regional de Educación de Adultos. Temas de Educación de Adultos. Ano I, n.2. Caracas, Venezuela, 1972.

, Malcolm S. The Modern Practice of Adult Education; From Andragogy to Pedagogy. Englewood Cliffs, NJ: Cambridge Adult Education. 1980.

Malcom. Andragogy in action. Applying modern principles of adult education.

San Francisco: Jossey-Bass. 1984.

SILVA, T. R. da. A educação de adultos em análise: estudo de caso das novas oportunidades. Universidade do Minho Escola de Economia e Gestão. Portugal, 2012. 